\title{
Current Distribution Mapping for PEMFCs
}

\author{
S. Shimpalee ${ }^{1}$, V. Lilavivat ${ }^{2}$ and J. W. Van Zee ${ }^{3}$ \\ Department of Chemical Engineering, \\ University of South Carolina, Columbia, SC 29208
}

H. Xu and C. K. Mittelsteadt

Giner, Inc.

89 Rumford Avenue, Newton, MA 02466

Submitted to

Professor Shi-Gang Sun

Associate Editor

Electrochimica Acta

Revised version: May 25, 2015

1- Corresponding author: Phone: (803) 576-6140; FAX: (803) 777-8142, e-mail: shimpale@ cec.sc.edu

2- Present address: MTEC, National Science and Technology Development Agency (NSTDA) 114 Thailand Science Park, Pathum Thani, 12120, Thailand

3- Present address: Dept. of Chemical and Biological Engineering, University of Alabama, Tuscaloosa, Al. 


\begin{abstract}
A developed measurement system for current distribution mapping has enabled a new approach for operational measurements in proton exchange membrane fuel cells (PEMFCs). Currently, there are many issues with the methods to measure current distribution; some of the problems that arise are breaking up the fuel cell component and these measurements are costly. Within this field of work, there is a cost effective method and an easy technique of mapping the current distribution within a fuel cell while not disrupting reactant flow. The physical setup of this method takes a current distribution board and inserts it between an anode flow field plate and a gas diffusion layer. From this layout, the current distribution can be directly measured from the current distribution board. This novel technique can be simply applied to different fuel cell hardware. Further it also can be used in fuel cell stack by inserting multiple current distribution boards into the stack cells. The results from the current distribution measurements and the electrochemical predictions from computational fluid dynamics modeling were used to analyze water transports inside the fuel cell. This developed system can be a basis for a good understanding of optimization for fuel cell design and operation mode.
\end{abstract}

Keywords: Proton Exchange Membrane Fuel Cell (PEMFC); Current Distribution; Segment; Fuel Cell Simulation 


\section{Introduction}

Fuel cells are an energy conversion device that directly converts chemical energy into electricity by electrochemical process. The proton exchange membrane fuel cells (PEMFCs) that operate at significantly low temperatures are one of the most promising future power sources for their high efficiency and energy density among the fuel cell candidates $[1,2]$. The PEMFCs are being developed as a sustainable alternative that have a variety of applications such as automotive and stationary power. It is well known that the current distribution in PEMFC is not uniform. This non-uniformity of current distribution in PEMFC can cause the loss of performance, the starvation process within a fuel cell, and the membrane degradation which leads to a reduced lifetime of the PEMFCs [3]. The water accumulation along flow-field can also cause the non-uniformity of current distribution [4-7] and it is a major problem in maintaining high performance in the PEMFCs [8].

There are several methods of measuring current distribution in PEMFCs including the segmented electrode cell which is an invasive design construction. Current distribution measurement can be categorized into three major techniques: printed circuit board, resistors network, and Hall-effect sensors [9]. These techniques require segmentation of one or both of the current collector and the bipolar plate component. The printed circuit board technology $[10,11]$ was introduced by Cleghorn et al. [10]. This technique uses a printed circuit board that is placed between the flow-field and the end plate for individual current collection. The resistors network technique [12-17] was introduced by Stumper et al. [13]. Basically, in the resistors network approach, either the anode or the cathode, or both sides are divided into the electrically isolated segments. These isolated segments are connected to the high resolution or shunt resistor network. The current from each segment can be calculated from the voltage drop across the resistor. The 
Hall-effect sensors technique [18, 19] was introduced by Weiser et al. [18]. This technique uses a magnetic loop array connected to the segmented current collector plate to measure current distribution in a PEMFC [18]. The magnetic loop array is working as a current transducer to measure current from the magnetic field induction around the conductor. Lin et al. [20] used commercial Current Scan Lin to measure the local temperature distribution within fuel cell. In their work, this high cost measurement was installed between cathode flow-field and current collector to protect from the flow path blockage and GDL damage. Their work was to measure the thermal and electrical behavior for both transient and steady state. Beside experimental works, several authors used mathematical models to predict water, temperature, and current distribution in PEMFCs [21-25]. These efforts included those predictions of distribution profiles across the membrane [26]. Model results have shown that local current distribution is dependent on local water and temperature profiles [21,27].

Although numerous in-situ measurements of current distribution have been reported, most of those methods for current mapping may block the flow path, break diffusion media, and/or are very expensive. Therefore in this work, the cost-effective method and the simple approach of mapping the current distribution in a PEMFC was developed that will overcome many of the above limitations. This work aims to use the innovative measurement system [28] for the mapping of current distribution in the PEMFC as well as the understanding of water transport when the fuel cell is being operated.

There are many factors that affect the current distribution in PEMFC such as the difference in humidification temperature, gas flow rate, and gas flow arrangement. The bipolar plate design has a significant effect on overall PEMFC performance [4, 5]. They achieves the function of current collector, mechanical support for MEA, and provides access channel for the 
fuel and oxidant to PEMFC. The main challenge of current distribution mapping design is to attain the function of the bipolar plate which allows the reactant gases to access the MEA and also allow the current to be measured individually.

The purpose of this work is to establish a reliable and non-invasive method of measuring current distribution in a PEMFC. To demonstrate the capability of our current distribution mapping design, computational fluid dynamic (CFD) predictions of local current density and transport variables were introduced and discussed along with the experimental data.

\section{Current distribution measurement system}

The novel developed current distribution measurement system consists of three main parts: current distribution broad (CDB) device, Hall-effect sensor, and data acquisition. Figure 1 shows the simplified schematic of the measurement system in this work. CDB device, which was positioned within the fuel cell stack, was used for monitoring of the current density distribution.

\subsection{Current distribution board device}

The fuel cell used for this current distribution experiment has an active area of $50 \mathrm{~cm}^{2}$ made by Fuel Cell Technology, Inc. [29], which integrated triple serpentine flow fields on the anode side and quadruple serpentine flow fields on the cathode side. The CDB was designed to work with this cell without disturbing the flow inside the gas channels.

To measure the current distribution, the $\mathrm{CDB}$ was designed and installed between the anode gas diffusion layer (GDL) and the anode flow-field plate as shown in Figure. 2. Figure 2a presents the anode flow-field plate before installing the CDB and it shows flow direction from inlet to outlet. Figure $2 \mathrm{~b}$ shows the anode flow-field after installing the CDB. This figure also presents how each segment is divided and numbered for further analysis. Figure $2 \mathrm{c}$ shows that 
the CDB can be simply made and installed to any fuel cell hardware for a variety studies (e.g., transport, heat, and contamination). However, in this paper the $50-\mathrm{cm}^{2}$ serpentine flow-field hardware is the primary focus. Figure 3 shows the assembly of the fuel cell with the CDB. The CDB was placed with the conducting material facing the anode side to measure the local current. With the very low lateral proton conductivity of typical thickness of the membrane used in the fuel cells, we can assume that the anode current is the same as cathode current $\left(i_{x y}(\right.$ cathode $)=$ $\mathrm{i}_{\mathrm{xy}}($ anode)). This current distribution board was designed to have the cutout regions areas align with flow channel of the bipolar plate to avoid obstruction of gas during the fuel cell operation (see Figure 2b). This particular $\mathrm{CDB}$ is capable of measuring for 10 individual areas. Each current collector segment has an area of $5 \mathrm{~cm}^{2}$. Figure 4 shows the schematic of CDB components. This CDB consists of three layers: base, conductor, and insulation tape. A $50 \mu \mathrm{m}$ Kapton ${ }^{\circledR}$ board was used as the base layer. The conductor consisting of copper bonded to the Kapton®. In order to prevent the corrosion during operational measurement, the copper segment was gold plated. Finally, $50 \mu \mathrm{m}$ of Kapton ${ }^{\circledR}$ tape was used as an insulator to eliminate the conduction from material itself over the 10 individual current collection regions. Also, Kapton ${ }^{\circledR}$ tape insulates the copper conductor and maintains uniform thickness around the perimeter of the board to prevent leaks during operation.

Figure 5 shows the CDB adaptors, which are designed to have excellent contact between the board and the current-carrying wire. This figure also illustrates the direction of current during operation and the contact points that the current will travel. The first contact point occurs between the $\mathrm{CDB}$ and a lug. Each lug allows two points of measurement for each of the 10 regions such that of both current and voltage measurements. To provide a good corrosion resistance of these lugs, they were also coated with a gold flash completely coating the surface 
area. Therefore, the contact point between the lug and the current-carrying wire resistance was small due to excellent contact between the lug and the wire.

\subsection{Calibration of sensors}

In order to verify the setup and the testing method, a mock test was used to collect the current distribution when using either a cut gas diffusion layer (GDL) or uncut GDL. This method was reported previously [28]. The purpose of this test is to examine the conductivity nature of the GDL by looking for a "smear "caused from current onto another section. The test was conducted where three amps of current were applied to the top of each segment via a DC power supply. Then, the current was measured from each segment; a significant amount of current was able to travel laterally through the GDL into nearby segments. Through experimentation, results were more accurate with individually segmented GDL. The GDL, AvCarb® EP40T, was segmented by cutting it into 10 pieces to prevent current leakage between nearby segments, and it is same size as the current collector area of $5 \mathrm{~cm}^{2}$. The 3 -amp current was then applied to the electrode. The current was observed and recorded with the results showing a maximum of $0.9 \%$ error from the true applied current of 3-amp.

\subsection{Hall-effect sensor and data acquisition.}

The Hall-effect sensors were used to measure current for the CDB device. To monitor the current distribution in the fuel cell, the current was measured from individual segments separately by the Hall-effect sensors in the Hall-effect box as shown in Figure 6. The Hall-effect box consists of 10 Hall-effect sensors connected to the primary load box (Scribner Fuel Cell Test System 850e). This allowed the measuring of the current from ten individual segments in the CDB separately. 
The data acquisition (DAQ) board was used to collect and monitor data during the experiment. This DAQ is able to measure 10 current inputs and also ten potential inputs simultaneously at 16 bits. The DAQ was connected to the computer and monitored by LabVIEW program. When running the experiment, the fuel cell was operated by controlling the potential, which was measured from "wire to load box" at Hall-effect sensors box shown in Figure 6.

\section{Experimental Procedure}

A PEMFC with an active area of $50 \mathrm{~cm}^{2}$ was used in the study. The fuel cell assembly consists of an anode bipolar plate, current distribution board, 10 segmented anode GDLs (AvCarb® EP40T), membrane electrode assembly (MEA), un-segmented cathode GDL (AvCarb® EP40T), and a cathode bipolar plate as shown in Figure 3. The Gore ${ }^{\mathrm{TM}} 57$ Series MEA, with platinum loadings of $0.1 \mathrm{mg} / \mathrm{cm}^{2}$ on the anode and $0.4 \mathrm{mg} / \mathrm{cm}^{2}$ on the cathode, was used in the experiment. Table 1 summarizes the geometry details used in this experiment.

The current distribution was measured by using the CDB while the fuel cell was running at various humidity conditions to investigate the effect of humidification on the local performance. To define the humidity condition, the inlet gas dew point temperature was controlled by a fuel cell test station. The operating temperature was always set at $80^{\circ} \mathrm{C}$ with the stoichiometry number of 1.5 at the anode and 2.0 at the cathode with co-flow configuration for all following experiments. The relative humidity condition of inlet gas was considered as the varying parameter. All of the experimental conditions are summarized in Table 2.

\section{Model development}

A computational continuum mechanics (CCM) technique based on a commercial flow solver, STAR-CD 4.18, was used to solve the coupled governing equations[30]. This software 
has an add-on tool called expert system of proton exchange membrane fuel cell (ES-PEMFC) version 2.50 that incorporates multi-physics of PEMFC. These require the source terms for species transport, multiphase flow, and heat generation equations [4, 5, 26, 31, 32]. This model has been validated with experimental data and the results were satisfied in both polarization data [32] and water balance data [26].

Further, the numerical simulation of PEMFC was performed in this work to compare with segmented data taken from CDB. The model geometry used in the simulation was exactly the same used in the experiment. It consists of anode and cathode flow-fields separated by GDLs and a MEA. The geometry details used in this simulation are also given in Table 1 . The operating conditions input into the model were consistent with experimental conditions given in Table 2. The number of computational cells used in the model is about one million cells. The predictions of current density distributions were compared with the experimental results taken from the CDB. The analysis of the results using both experimental and numerical information under various conditions was also discussed.

\section{Results and discussion}

Figure 7 shows the resistance chart of the fuel cell when the CDB was installed. The total excess of $6 \mathrm{~m} \Omega$ was obtained, which comes from the wires, the connection adapter and the CDB. Consequently, when taking this excess resistance into account, all resistance corrected polarization curves should be similar to the data without the CDB installed as shown in Figure 8. This figure shows the polarization curves of the PEM fuel cell with and without CDB for different humidity conditions (a) Anode $25 \% \mathrm{RH}$, Cathode $25 \% \mathrm{RH}$, b) Anode $75 \% \mathrm{RH}$, Cathode 25\%RH, and c) Anode 100\%RH, Cathode 50\%RH., 5 psig back pressure). The overall performance of these three operating conditions reveals that the inlet humidity condition of 
$25 \% \mathrm{RH}$ anode $125 \% \mathrm{RH}$ cathode leads to the lowest performance. Then the performance of PEMFCs increases once the inlet humidity of the anode and/or the cathode is increased. In this particular experiment, the maximum performance is achieved when the anode inlet humidity is $100 \% \mathrm{RH}$ and the cathode inlet humidity is $50 \% \mathrm{RH}$ with back pressure of 5 psig. The enhancement of performance for this particular condition comes from the increasing of both inlet humidity and partial pressure of reacting gases. Moreover, this figure also presents the model prediction of IR corrected polarization curves compared to the experiment data and all predicted curves show good agreement with the data for all cases.

During fuel cell testing, the local current at 10 segments on CDB was recorded. Figure 9 shows the performance curve of each segment at different inlet humidity conditions similar to Figure 8. From these figures, the local polarization curves from segmented experiments can be presented in different profiles when the operating condition changes. For the dryer condition of 25\%RH anode/25\%RH cathode as shown in Figure 9a, the Segments 1 and 2 show the lowest local performance and the Segments 7 to10 display the highest local performance. Meanwhile when the operating condition was changed to higher relative humidity as presented in Figures $9 \mathrm{~b}$ and 9c, the Segments 1 to 4 show the highest local performance and the Segment 10 presents the lowest local performance. Further discussion of these behaviors will be given in Figures 10 to 12.

Figure 10 shows the local current densities at ten segments at different humidity conditions compared with the numerical predictions. Note that the flow direction and the flowfield path corresponding to each segment on the CDB can be found in Figure 2. Figure 10a represents the current densities at $25 \% \mathrm{RH}$ on both the cathode and anode. The cell potential was set at $0.3 \mathrm{~V}$ with a cell temperature of $80^{\circ} \mathrm{C}$. The maximum current density is observed at the 
outlet regions where Segments 7 to 10 are located. This experimental result is consistent with the model prediction as also shown in this figure. In this particular operating condition where the dryer inlet humidity was introduced into both anode and cathode, the water back diffusion from the cathode to the anode shows strong contribution, thus resulting in higher membrane water content and increasing the local performance toward the exit. Figure 11 shows the distributions of numerical prediction of total water flux across the membrane. There are positive and negative values indicating the direction of the flux. The positive value indicates that the water transports from the anode to the cathode and the negative number denotes water back diffusion, where the direction of water transport is from the cathode to the anode. Figure 12 shows the prediction of local temperature distributions on the cathode MEA surface. Figure 11a supports the explanation given in Figure 10a that water back diffusion is presented in this condition. Therefore, the local current density increases from the inlet toward the outlet due to increasing membrane conductivity. However, the temperature distribution seems to be uniform with slightly increases toward the exit region. This could be the change in local current density is relatively small compared to other conditions.

When the inlet humidity at the anode was increased to $75 \% \mathrm{RH}$ while keeping the cathode inlet humidity constant at $25 \% \mathrm{RH}$, the current distribution pattern in Figure $10 \mathrm{~b}$ is completely different from the profile shown in Figure 10a. The overall average current density is increased to $1.09 \mathrm{~A} / \mathrm{cm}^{2}$ at the cell potential of $0.3 \mathrm{~V}$. The highest current density is presented at locations 1 to 4 , where the anode inlet is located. Then the local current density is decreasing toward the outlet. The prediction also agrees well with experimental data in this particular study. By increasing the inlet humidity at the anode, the membrane water content and proton conductivity are also increased thus enhancing overall performance. When the membrane is well humidified, 
the local current density distribution decreases from the inlet to the outlet by following the consumption of hydrogen and oxygen in this co-current flow direction. Moreover, the water transport across the membrane follows the direction from the anode to the cathode due to the strong contribution of electro-osmotic flux rather than water back diffusion flux as shown in Figure 11b. This figure presents the net water flux across the membrane from the anode to the cathode as provided in the positive number. This value is decreased from the inlet toward the outlet as the current density is decreasing thus lowering the electro-osmotic flux. With current density distribution for this operating condition, the temperature distribution also shows the highest at the inlet region and it decreases toward the outlet as shown in Figure 12b.

The local current density profile shown in Figure 10c is similar to Figure 10b. A similar trend is also observed for the net water flux distributions shown in Figure 11b and Figure 11c, where the highest value is at the inlet region and the lowest value is located around the exit region. In Figure 10c, the average current density in this condition is higher (i.e., $1.25 \mathrm{~A} / \mathrm{cm}^{2}$ ) than the value shown in Figure 10b. This is because the inlet humidity condition in Figure 10c was increased to $100 \% \mathrm{RH}$ at the anode and $50 \% \mathrm{RH}$ at the cathode. Again, increasing humidity inside the PEMFC will enhance proton conductivity of the membrane thus increasing the overall performance. The numerical prediction agrees with the experimental results. When the local current density increases due to higher membrane water content, the net water flux from the anode to the cathode is also increased as shown in Figure 11c. With the increasing in current density, the heat of reaction is also increased thus raising the value of local temperature as given in Figure 12c. 


\section{Conclusions}

The current distribution was measured by using the CDB that can be placed inside a fuel cell with minimal obstruction and resistance. The CDB performance was verified using resistance collection. This technique was most consistent and matches the model prediction. The current distributions at various relative humidity conditions show different behaviors. The higher $\mathrm{RH}$ indicates higher overall current densities due to the lower membrane resistance. For high $\mathrm{RH}$, the results also indicated the maximum current density at the inlet regions and lower current density towards the outlet regions of the cell. On the other hand, for low $\mathrm{RH}$, the result shows the lowest current density at the inlet regions and higher current density towards the outlet regions of the cell. The CFD predictions agree with the experimental data. Consequently, the electrochemical variables from the model results can be used for further analysis. This novel technique of measuring the current density distribution using CDB sheet can be applied to any type of fuel cell hardware and with less effort.

\section{Acknowledgement}

The authors would like to acknowledge Giner, Inc., Tech-Etch, Inc., AvCarb Material Solutions, CD-adapco, and Altair Engineering, Inc. They also would like to thank the Department of Energy (grant \# DE-EE0000471) for their financial supports. 


\section{References}

[1] V. Mehta, J.S. Cooper, Journal of Power Sources, 114 (2003) 32-53.

[2] C.Y. Wang, Chemical Reviews, 104 (2004) 4727-4765.

[3] L. You, H. Liu, Int J Heat Mass Tran, 45 (2002) 2277-2287.

[4] D.H. Jeon, S. Greenway, S. Shimpalee, J.W. Van Zee, Int J Hydrogen Energ, 33 (2008) 1052-1066.

[5] S. Shimpalee, V. Lilavivat, J.W. Van Zee, H. McCrabb, A. Lozano-Morales, Int J Hydrogen Energ, 36 (2011) 12512-12523.

[6] Y.G. Yoon, W.Y. Lee, T.H. Yang, G.G. Park, C.S. Kim, Journal of Power Sources, 118 (2003) 193-199.

[7] F.N. Buchi, A.B. Geiger, R.P. Neto, Journal of Power Sources, 145 (2005) 62-67.

[8] U. Pasaogullari, C.Y. Wang, J Electrochem Soc, 151 (2004) A399-A406.

[9] L.C. Perez, L. Brandao, J.M. Sousa, A. Mendes, Renew Sust Energ Rev, 15 (2011) 169-185.

[10] S.J.C. Cleghorn, C.R. Derouin, M.S. Wilson, S. Gottesfeld, J Appl Electrochem, 28 (1998) 663-672.

[11] I. Alaefour, G. Karimi, K. Jiao, X. Li, Appl Energ, 93 (2012) 80-89.

[12] M. Noponen, T. Mennola, M. Mikkola, T. Hottinen, P. Lund, Journal of Power Sources, 106 (2002) 304-312.

[13] J. Stumper, S.A. Campbell, D.P. Wilkinson, M.C. Johnson, M. Davis, Electrochimica Acta, 43 (1998) 3773-3783.

[14] M.M. Mench, C.Y. Wang, M. Ishikawa, J Electrochem Soc, 150 (2003) A1052-A1059. [15] Y. Yu, X.-Z. Yuan, H. Li, E. Gu, H. Wang, G. Wang, M. Pan, Int J Hydrogen Energ, 37 (2012) 15288-15300. 
[16] D. Gerteisen, N. Zamel, C. Sadeler, F. Geiger, V. Ludwig, C. Hebling, Int J Hydrogen Energ, 37 (2012) 7736-7744.

[17] T.V. Reshetenko, G. Bender, K. Bethune, R. Rocheleau, Electrochimica Acta, 88 (2013) 571-579.

[18] C. Wieser, A. Helmbold, E. Gulzow, J Appl Electrochem, 30 (2000) 803-807.

[19] G.S. Zhang, S.L. Shen, L.J. Guo, H.T. Liu, Int J Hydrogen Energ, 37 (2012) 1884-1892.

[20] H. Lin, T.-F. Cao, L. Chen, Y.-L. He, W.-Q. Tao, Int J Hydrogen Energ, 37 (2012) 1187111886.

[21] T.E. Springer, T.A. Zawodzinski, S. Gottesfeld, J Electrochem Soc, 138 (1991) 2334-2342.

[22] T.F. Fuller, J. Newman, J Electrochem Soc, 140 (1993) 1218-1225.

[23] Z.H. Wang, C.Y. Wang, K.S. Chen, Journal of Power Sources, 94 (2001) 40-50.

[24] T.V. Nguyen, R.E. White, J Electrochem Soc, 140 (1993) 2178-2186.

[25] B. Carnes, D. Spernjak, G. Luo, L. Hao, K.S. Chen, C.-Y. Wang, R. Mukundan, R.L. Borup, Journal of Power Sources, (2013).

[26] W.K. Lee, S. Shimpalee, J.W. Van Zee, J Electrochem Soc, 150 (2003) A341-A348.

[27] T.E. Springer, M.S. Wilson, S. Gottesfeld, J Electrochem Soc, 140 (1993) 3513-3526.

[28] C.K. Mittelsteadt, P. Cortes, V. Lilavivat, S. Shimpalee, J.W. Van Zee, ECS Transactions, 41 (2011) 549-559.

[29] http://www.fuelcelltechnologies.com/fuelcell/products/single_cell_hardware.asp.

[30] C.A. Group, Star-CD 4.14 Methodology, in, CD Adapco Group.

[31] C.A. Group, ES-PEMFC 2.50 methodology and tutorial manual.

[32] S. Shimpalee, M. Ohashi, J.W. Van Zee, C. Ziegler, C. Stoeckmann, C. Sadeler, C. Hebling, Electrochimica Acta, 54 (2009) 2899-2911. 


\section{List of Tables}

Table 1. Geometry details

Table 2. Experimental condition 


\section{List of Figures}

Figure 1. Illustration of the hardware and software components of the system.

Figure 2. A photograph of the fuel cell bipolar plate a) $50-\mathrm{cm}^{2}$ anode serpentine flow field plate, b) alignment current distribution board on $50-\mathrm{cm}^{2}$ anode serpentine flow field plate, and c) CDB with different hardware

Figure 3. Assembly of fuel cell with Current Distribution Board in place.

Figure 4. The current distribution board component; consist of the 2-mil Kapton ${ }^{\circledR}$ tape, 2-mil conductor, and 2-mil Kapton® base.

Figure 5. Current distribution board with attached adaptors

Figure 6. The 10 individual collected currents pass through Hall-Effect sensors.

Figure 7. Schematic of the resistance chart in fuel cell operation with current distribution board.

Figure 8. Performance curves of PEMFC without CDB compared to performance curves of PEMFC with CDB after corrected for excess resistance.

Figure 9. Polarization curves of each segment under different humidity conditions: a) Anode 25\%RH, Cathode 25\%RH, b) Anode 75\%RH, Cathode 25\%RH, and c) Anode 100\%RH, Cathode 50\% RH.

Figure 10. Current density distributions of the three different inlet humidity conditions at potential $0.3 \mathrm{~V}$; a) Anode 25\%RH, Cathode 25\%RH, b) Anode 75\%RH, Cathode 25\%RH, and c) Anode $100 \%$ RH, Cathode 50\%RH, 5 psig.

Figure 11. Net water flux across the membrane $\left(\mathrm{mg} / \mathrm{cm}^{2}-\mathrm{s}\right)$ of three different inlet humidity conditions at potential of $0.3 \mathrm{~V}$. a) Anode $25 \% \mathrm{RH}$, Cathode 25\%RH, b) Anode $75 \% \mathrm{RH}$, Cathode $25 \% \mathrm{RH}$, and c) Anode 100\%RH, Cathode 50\%RH, 5 psig.

Figure 12. Temperature $(\mathrm{K})$ distribution on cathode MEA surface of three different inlet humidity conditions at potential of $0.3 \mathrm{~V}$. a) Anode $24 \% \mathrm{RH}$, Cathode $25 \% \mathrm{RH}, \mathrm{b}$ ) Anode $75 \% \mathrm{RH}$, Cathode 25\%RH, and c) Anode 100\%RH, Cathode 50\%RH, 5 psig. 
Table 1. Geometry details

\begin{tabular}{l|c}
\hline \multicolumn{1}{c|}{ Description } & Value \\
\hline Active area & $50 \mathrm{~cm}^{2}$ \\
Channel width & $0.8 \mathrm{~mm}$ \\
Channel height & $0.5 \mathrm{~mm}$ \\
Rib-spacing width & $0.8 \mathrm{~mm}$ \\
GDL thickness & $200 \mu \mathrm{m}$ \\
MEA thickness & $25 \mu \mathrm{m}$ \\
\hline
\end{tabular}


Table 2. Experimental condition

\begin{tabular}{cccccc}
\hline $\begin{array}{c}\mathrm{T}_{\text {cell }} \\
\left({ }^{\circ} \mathrm{C}\right)\end{array}$ & $\begin{array}{c}\text { Anode RH } \\
(\%)\end{array}$ & $\begin{array}{c}\text { Cathode RH } \\
(\%)\end{array}$ & $\begin{array}{c}\text { Stoichiometry } \\
\text { Anode }\end{array}$ & Cathode & $\begin{array}{c}\text { Back pressure } \\
(\mathrm{PSIG})\end{array}$ \\
\hline \multirow{2}{*}{80} & 25 & 25 & & & 0 \\
& 75 & 25 & 1.5 & 2.0 & 0 \\
& 100 & 50 & & & 5 \\
\hline
\end{tabular}



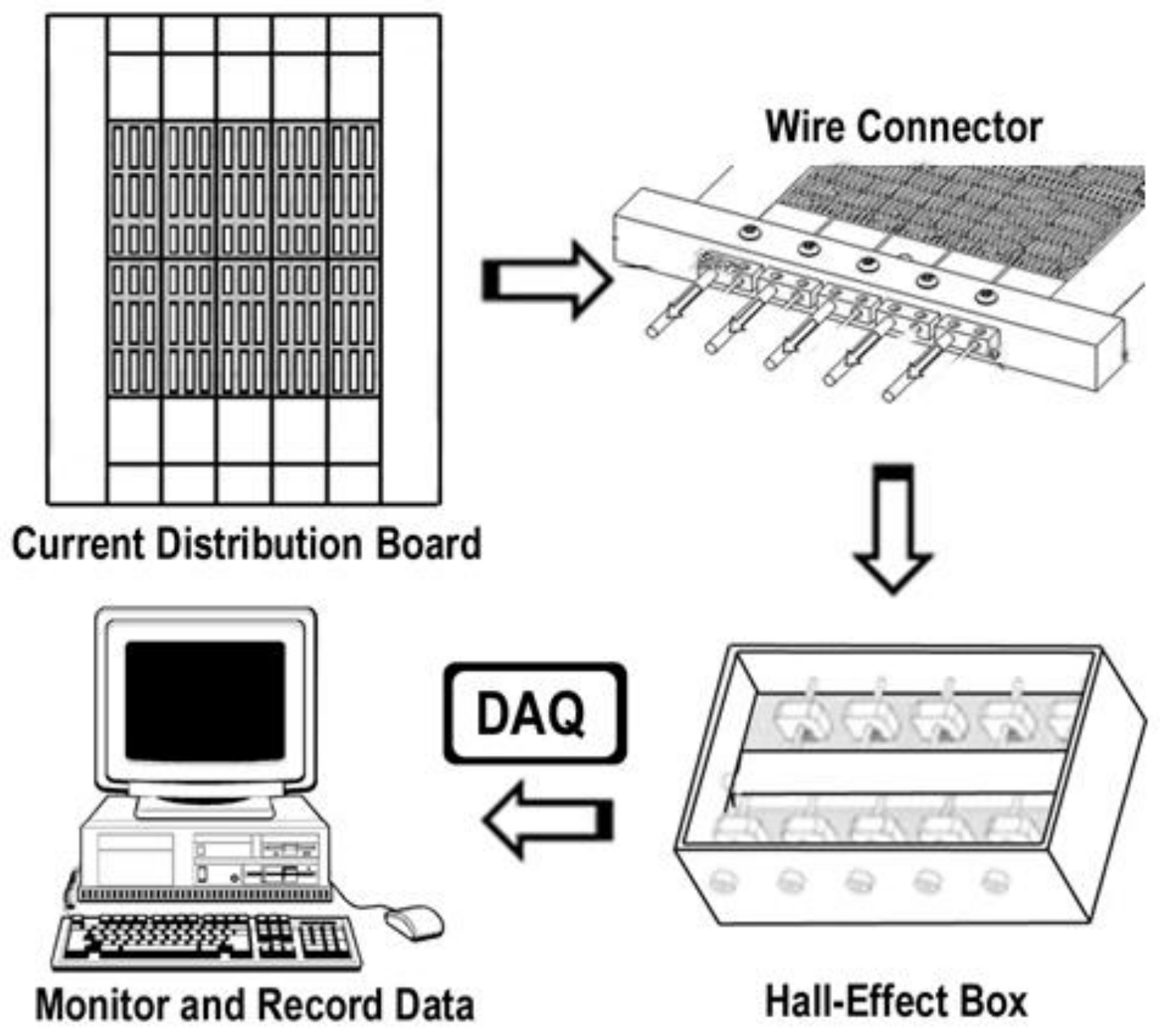

Figure 1. Illustration of the hardware and software components of the system. 


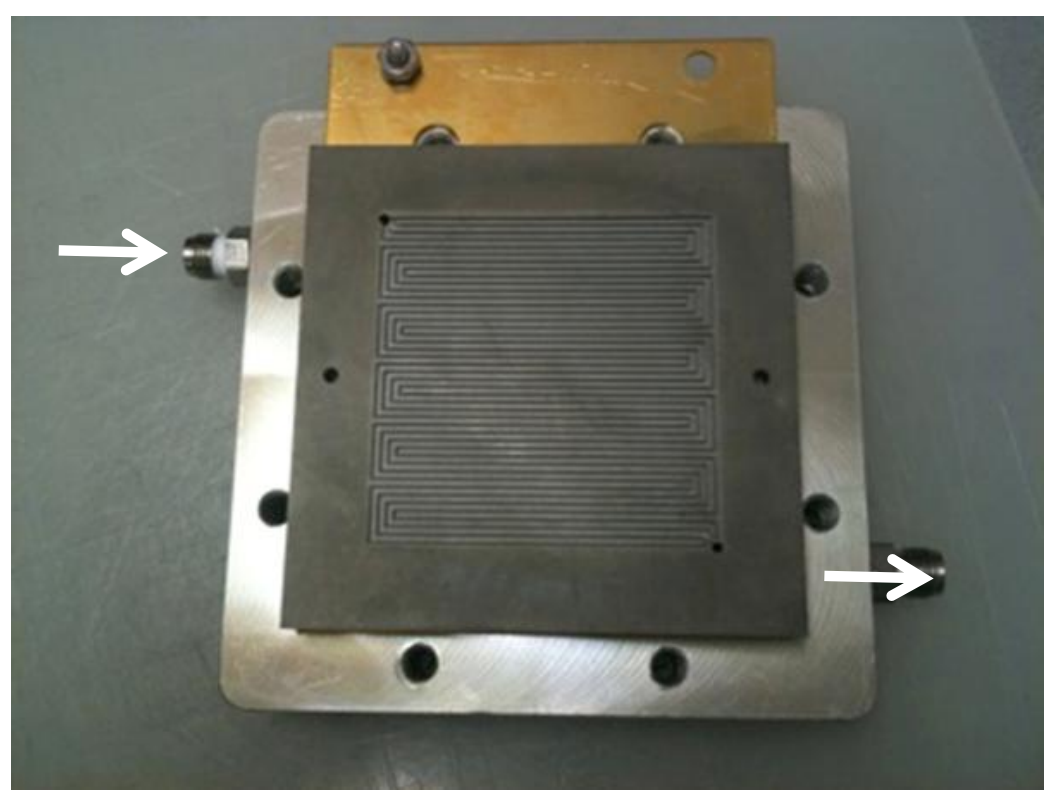

a) Anode flow-field plate

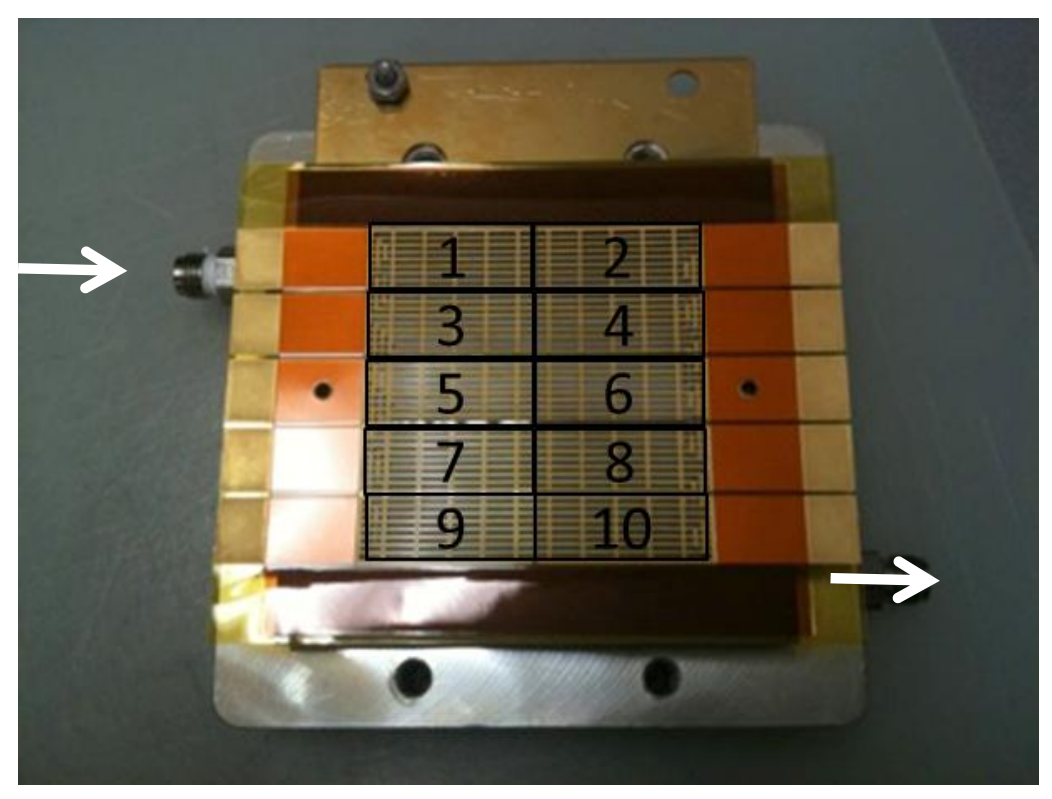

b) $\mathrm{CDB}$ on anode flow-field 


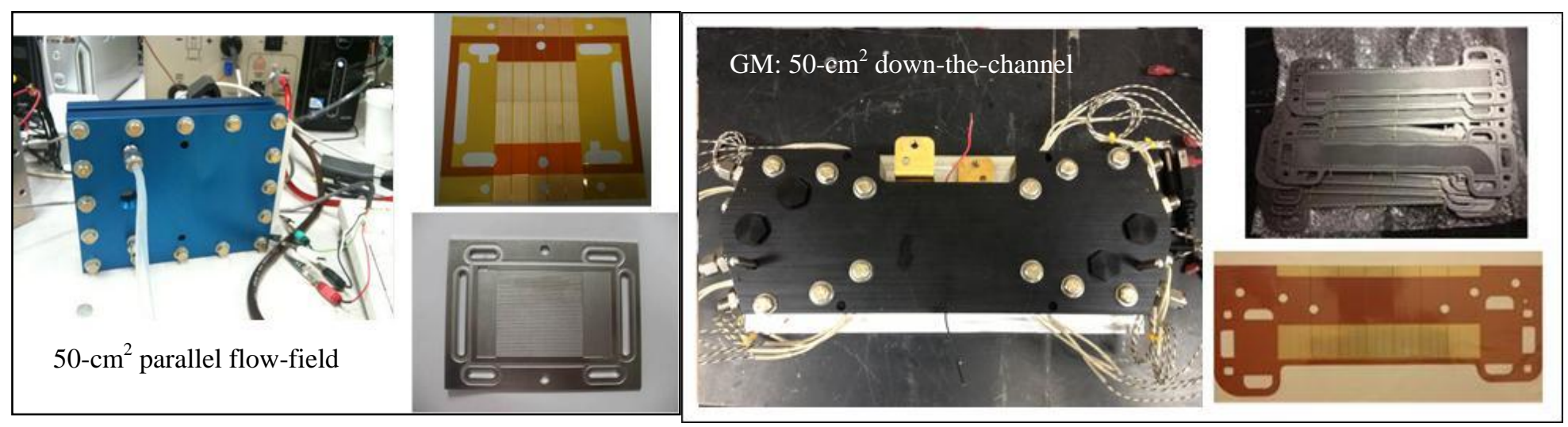

c) Fuel cell hardware

Figure 2. A photograph of the fuel cell bipolar plate a) $50-\mathrm{cm}^{2}$ anode serpentine flow field plate, b) alignment current distribution board on $50-\mathrm{cm}^{2}$ anode serpentine flow field plate, and c) CDB with different hardware 


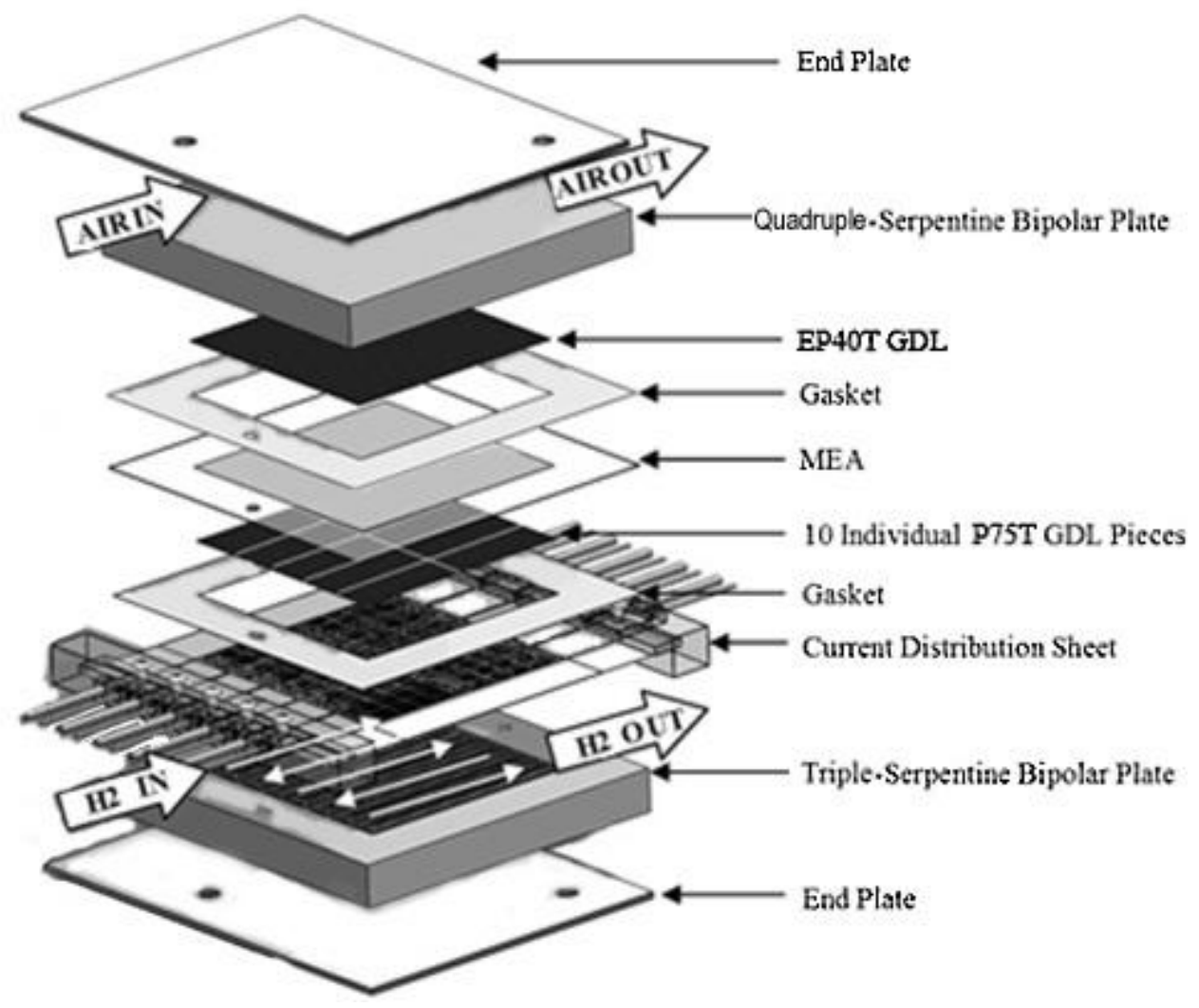

Figure 3. Assembly of fuel cell with Current Distribution Board in place. 


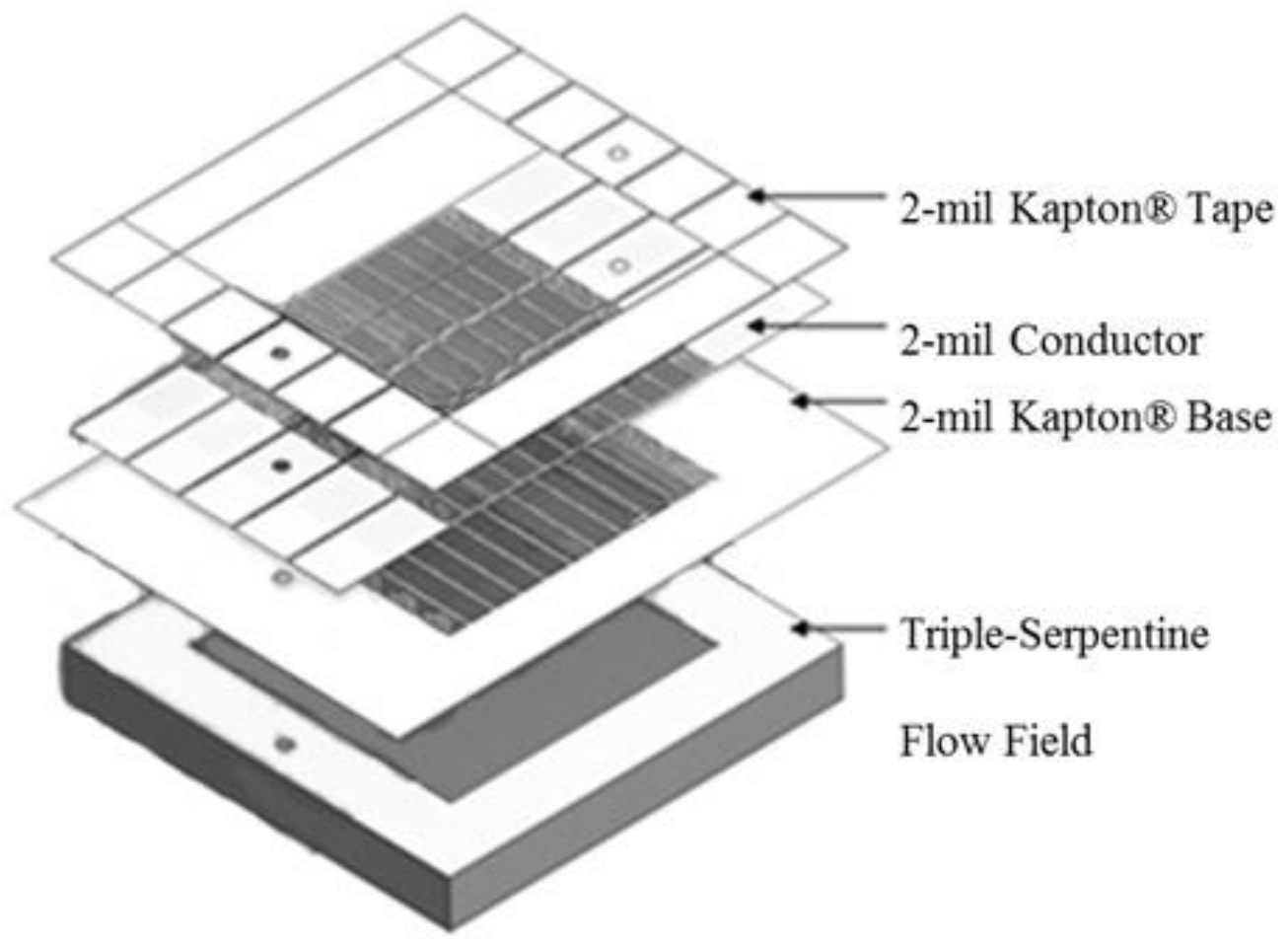

Figure 4. The current distribution board component; consist of the 2-mil Kapton ${ }$ tape, 2-mil conductor, and 2-mil Kapton® base. 


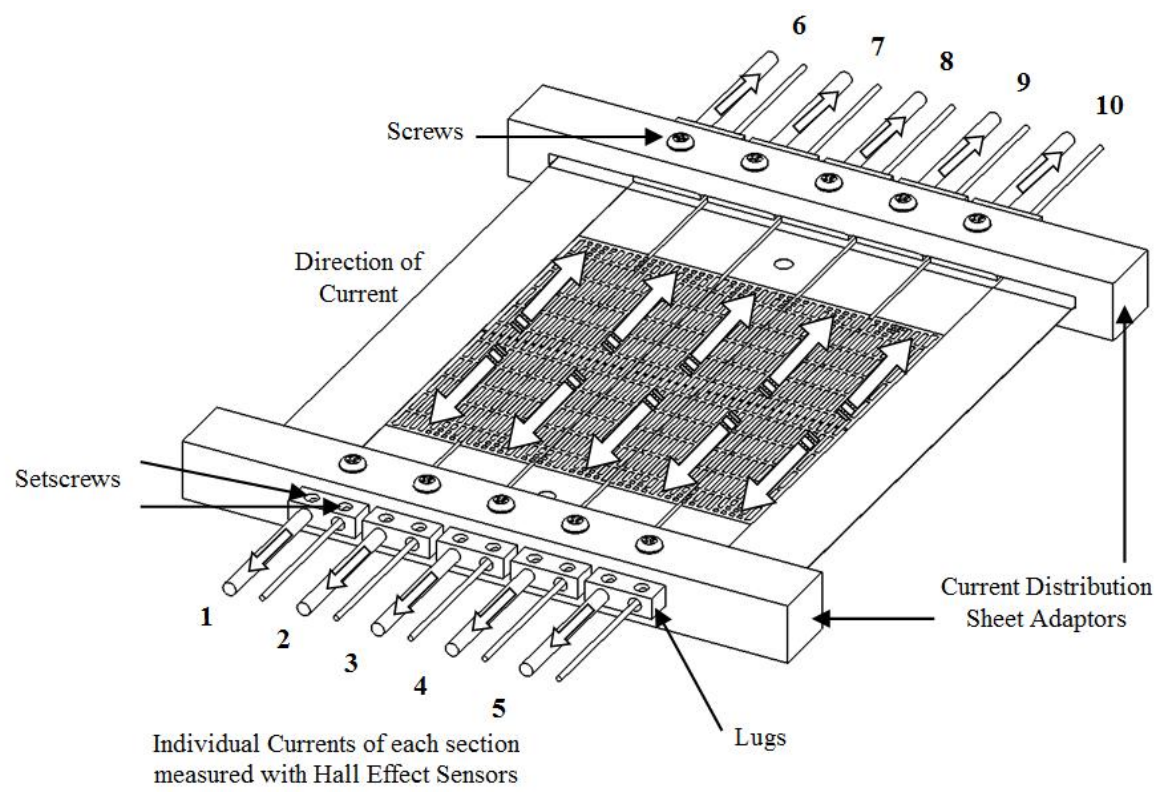

Figure 5. Current distribution board with attached adaptors 


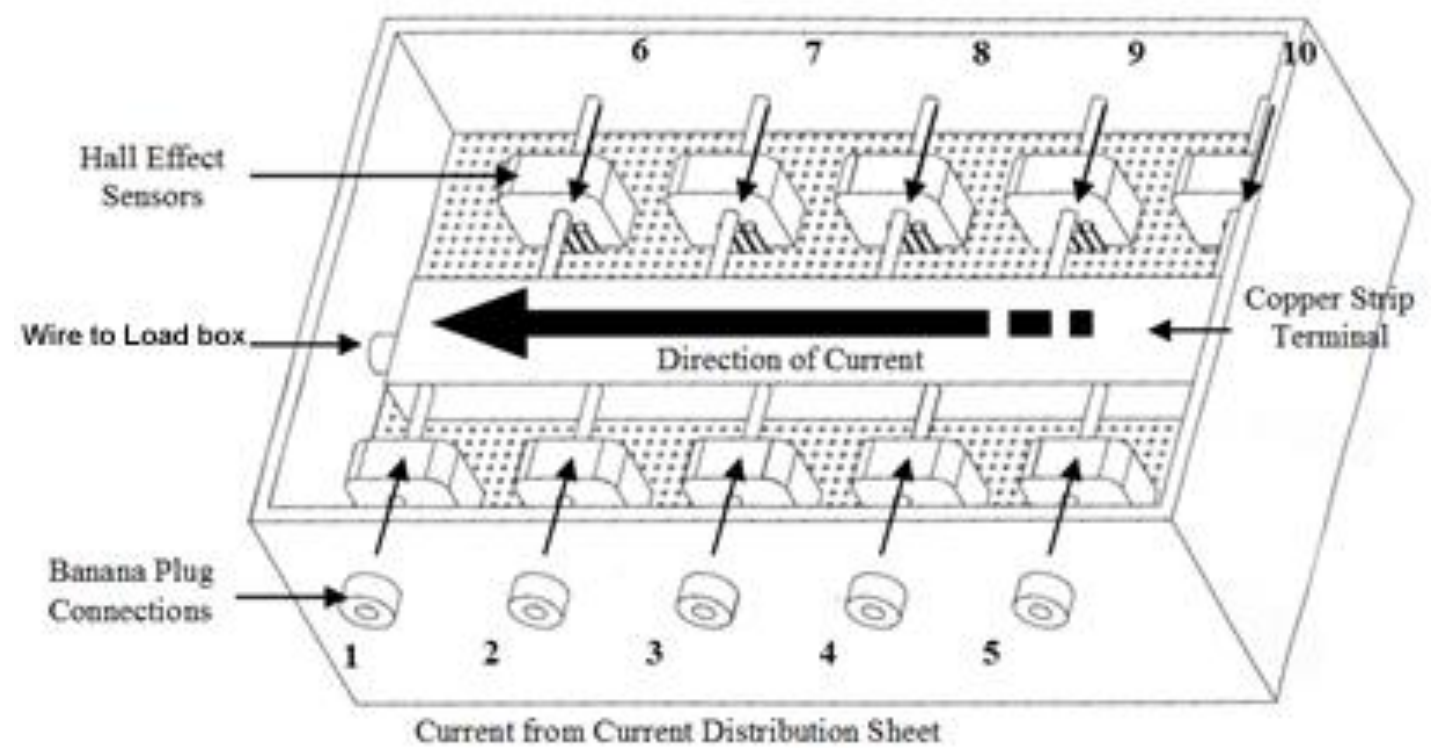

Figure 6. The 10 individual collected currents pass through Hall-Effect sensors. 


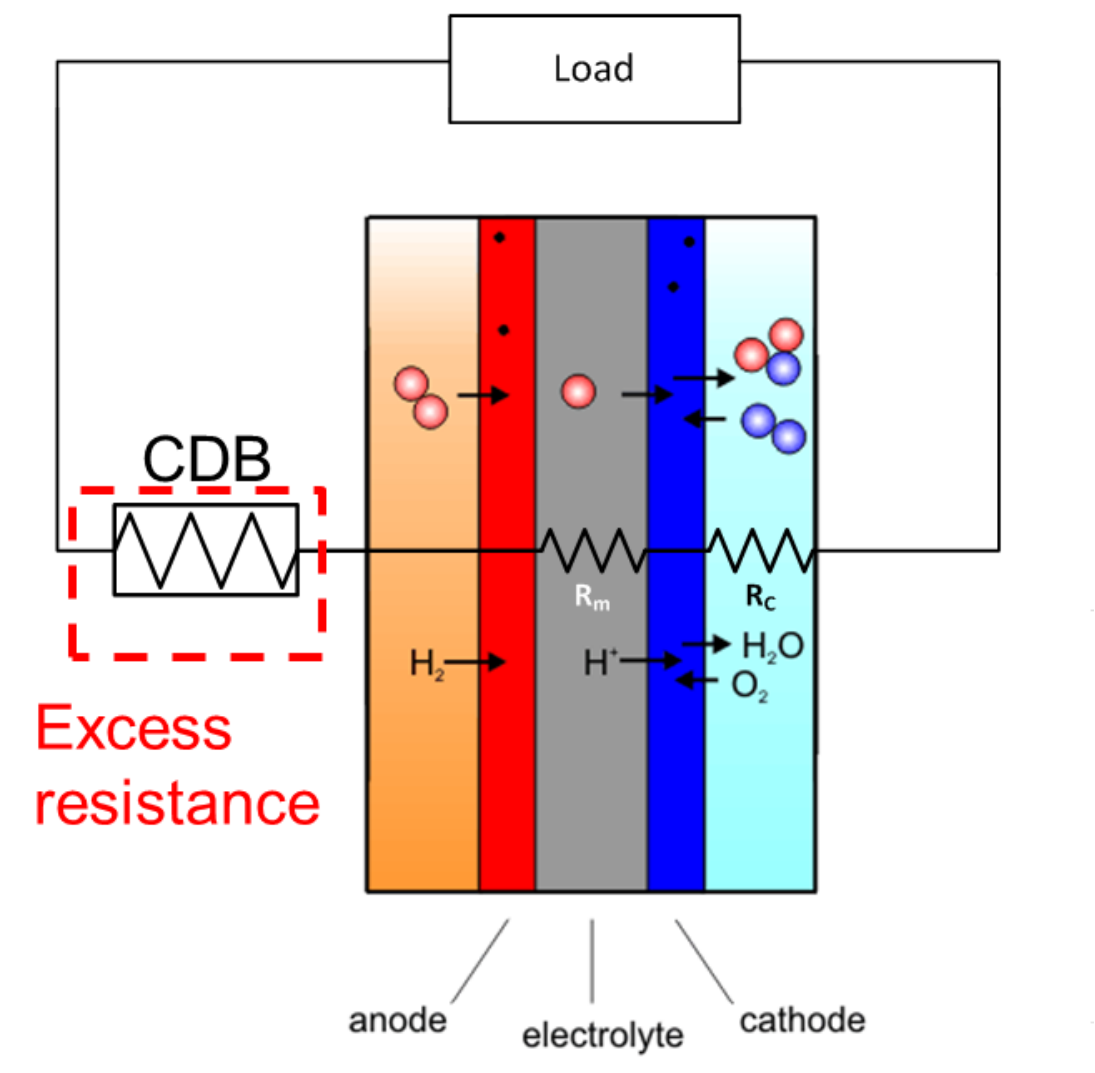

Figure 7. Schematic of the resistance chart in fuel cell operation with current distribution board. 


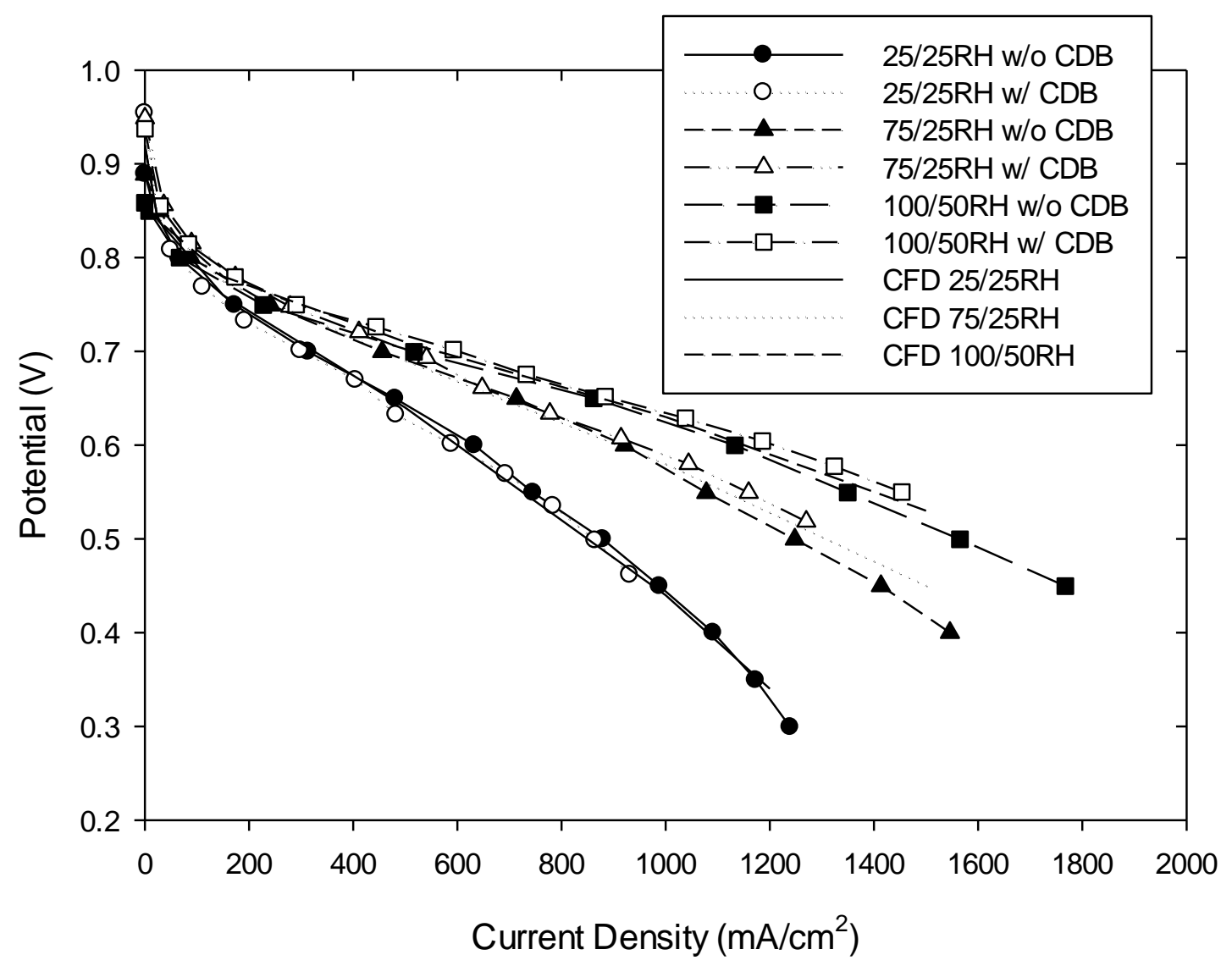

Figure 8. IR corrected performance curves of PEMFC without CDB compared to performance curves of PEMFC with CDB after corrected for excess resistance. 


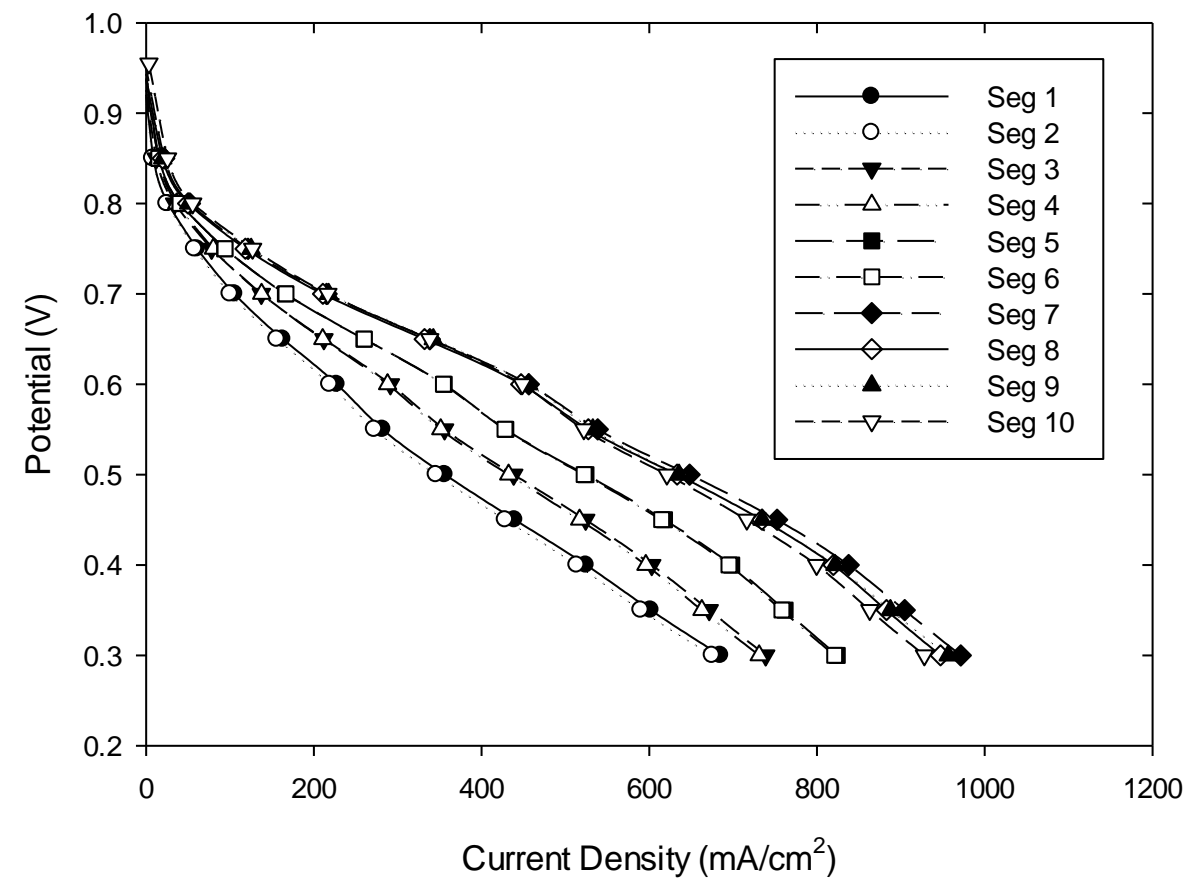

a) Anode $25 \% \mathrm{RH}$, Cathode $25 \% \mathrm{RH}$

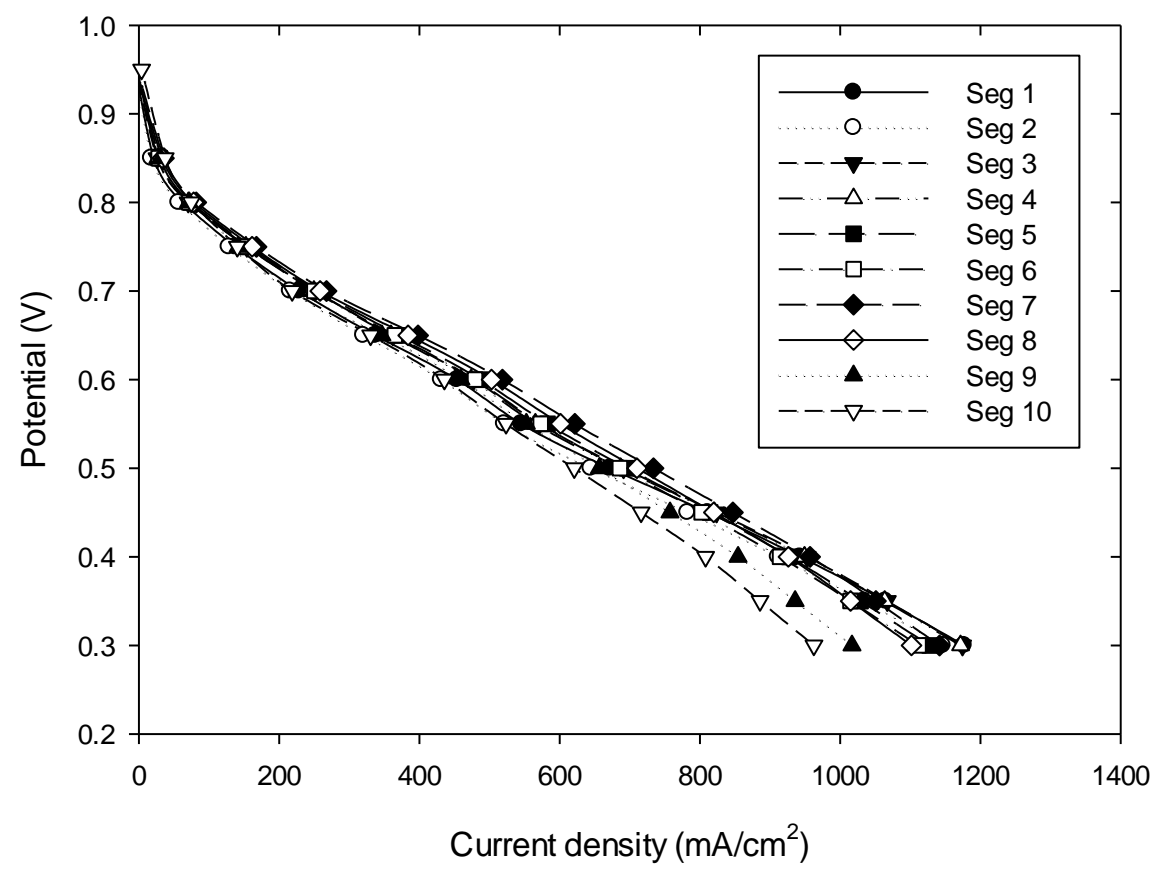

b) Anode $75 \% \mathrm{RH}$, Cathode $25 \% \mathrm{RH}$ 


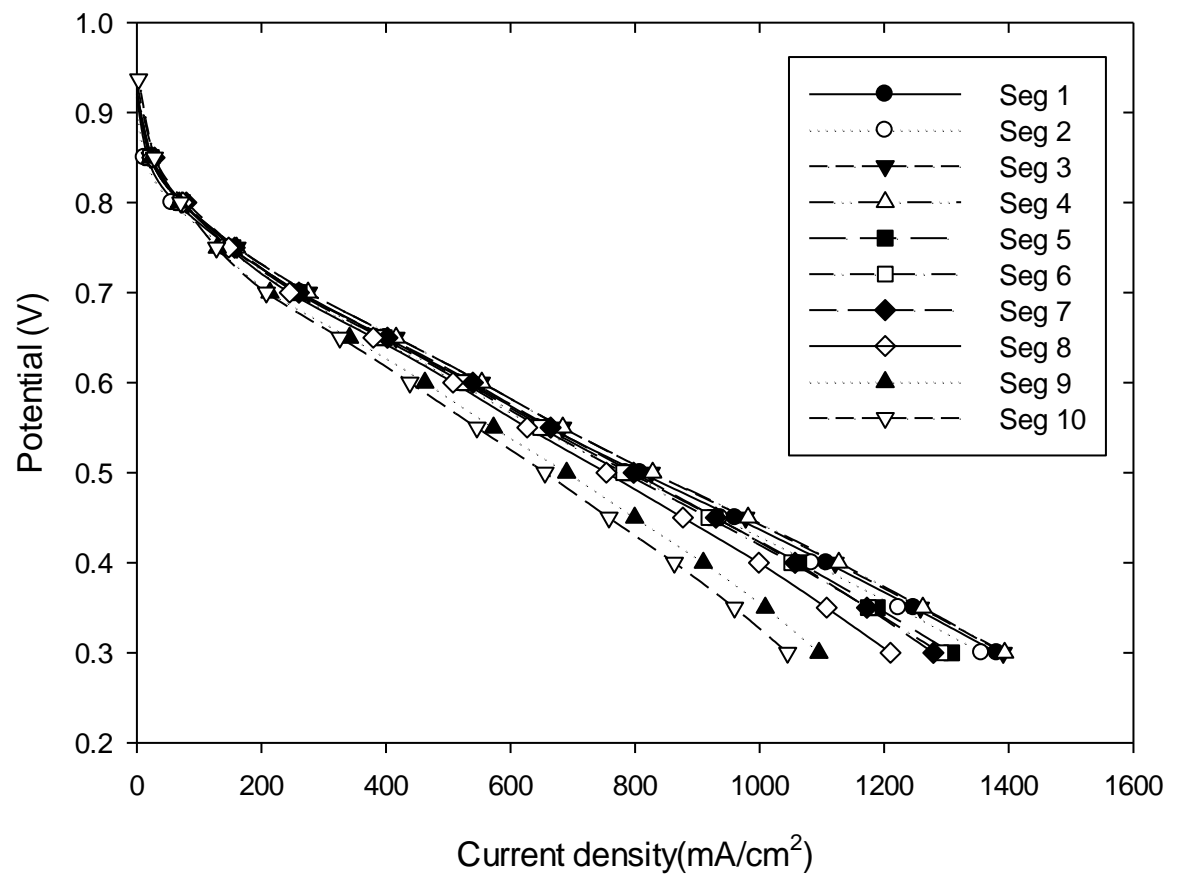

c) Anode $100 \% \mathrm{RH}$, Cathode $50 \% \mathrm{RH}$

Figure 9. Polarization curves of each segment under different humidity conditions: a) Anode 25\%RH, Cathode 25\%RH, b) Anode 75\%RH, Cathode 25\%RH, and c) Anode 100\%RH, Cathode $50 \% \mathrm{RH}$. 


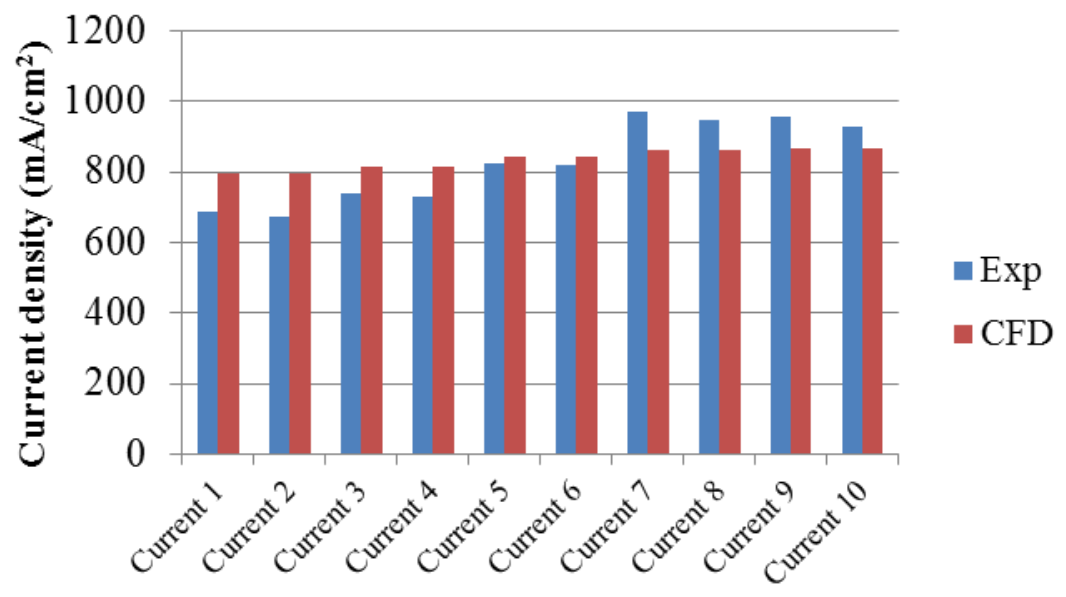

a) $\mathrm{I}_{\mathrm{avg}}=809 \mathrm{~mA} / \mathrm{cm}^{2}:$ Anode $25 \% \mathrm{RH}$, Cathode $25 \% \mathrm{RH}$

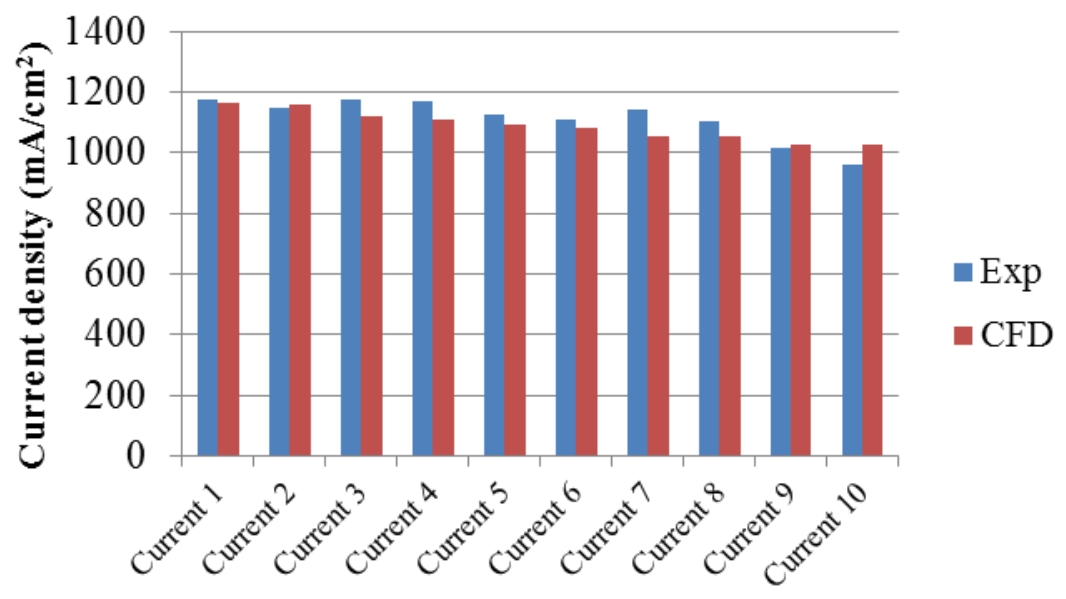

b) $\mathrm{I}_{\mathrm{avg}}=1094 \mathrm{~mA} / \mathrm{cm}^{2}$ : Anode $75 \% \mathrm{RH}$, Cathode $25 \% \mathrm{RH}$

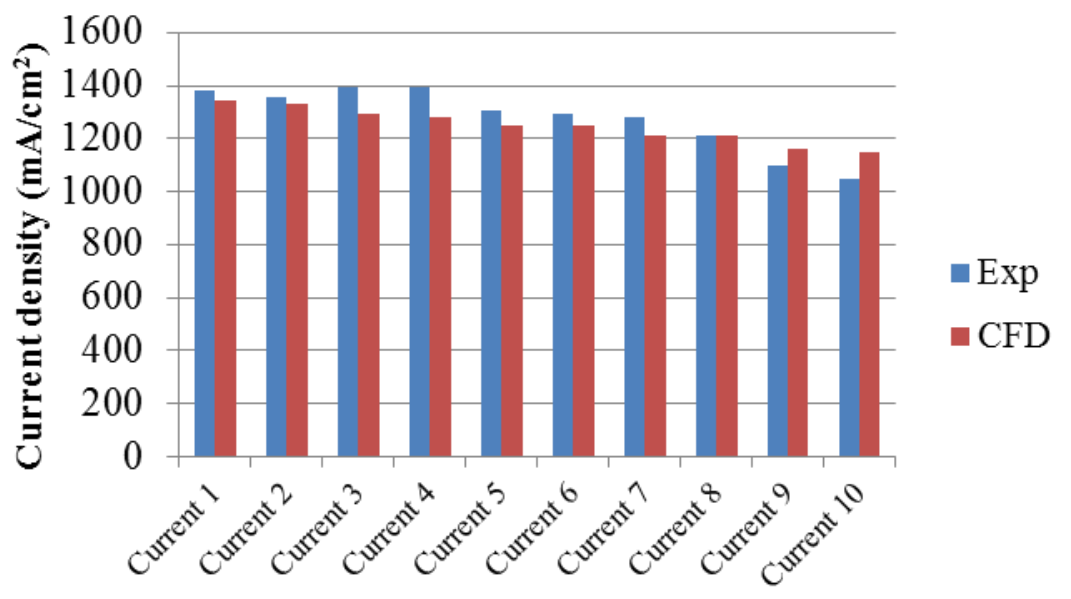

c) $\mathrm{I}_{\mathrm{avg}}=1250 \mathrm{~mA} / \mathrm{cm}^{2}$ : Anode $100 \% \mathrm{RH}$, Cathode $50 \% \mathrm{RH}, 5 \mathrm{psig}$.

Figure 10. Current density distributions of the three different inlet humidity conditions at potential 0.3V; a) Anode 25\%RH, Cathode 25\%RH, b) Anode 75\%RH, Cathode 25\%RH, and c) Anode 100\%RH, Cathode 50\%RH, 5 psig. 


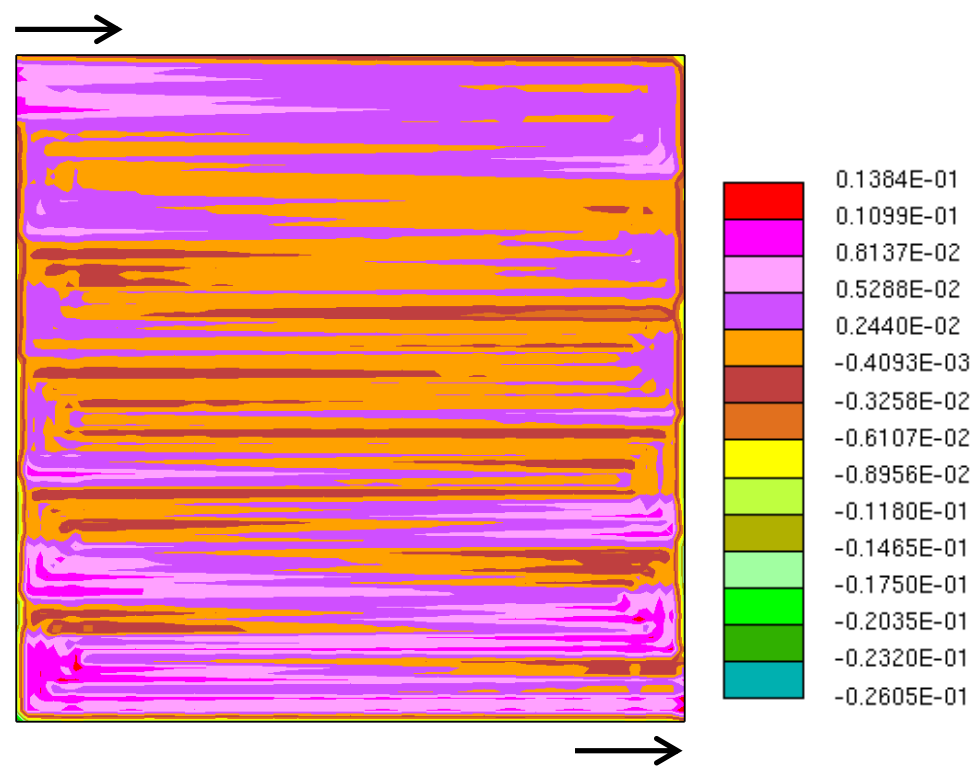

a) Anode $25 \% \mathrm{RH}$, Cathode $25 \% \mathrm{RH}$

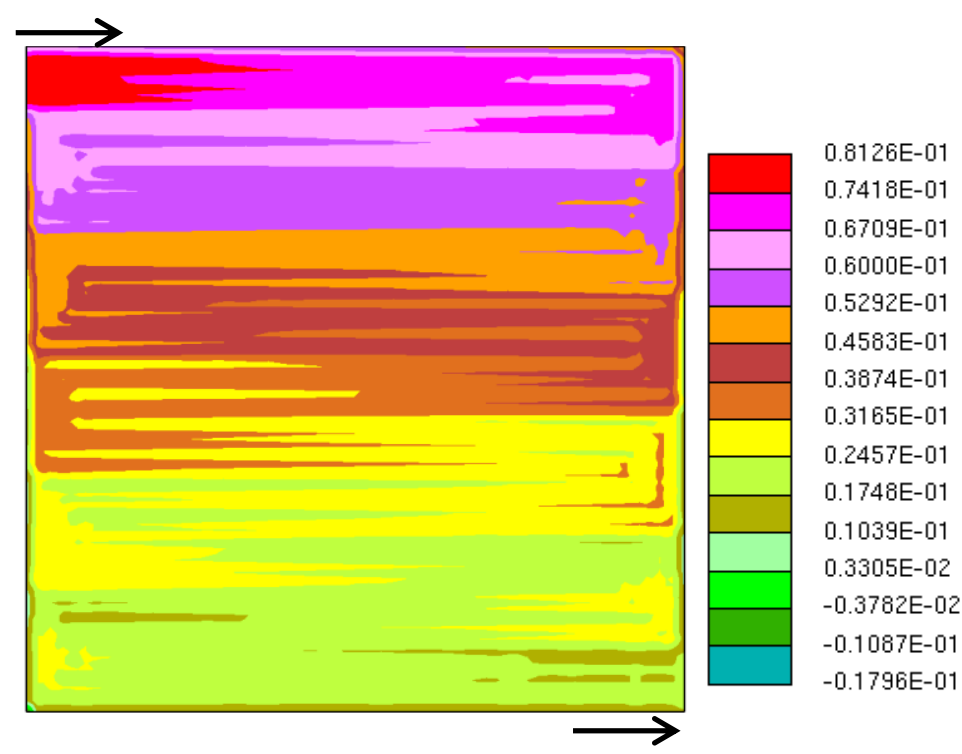

b) Anode $75 \% \mathrm{RH}$, Cathode $25 \% \mathrm{RH}$ 


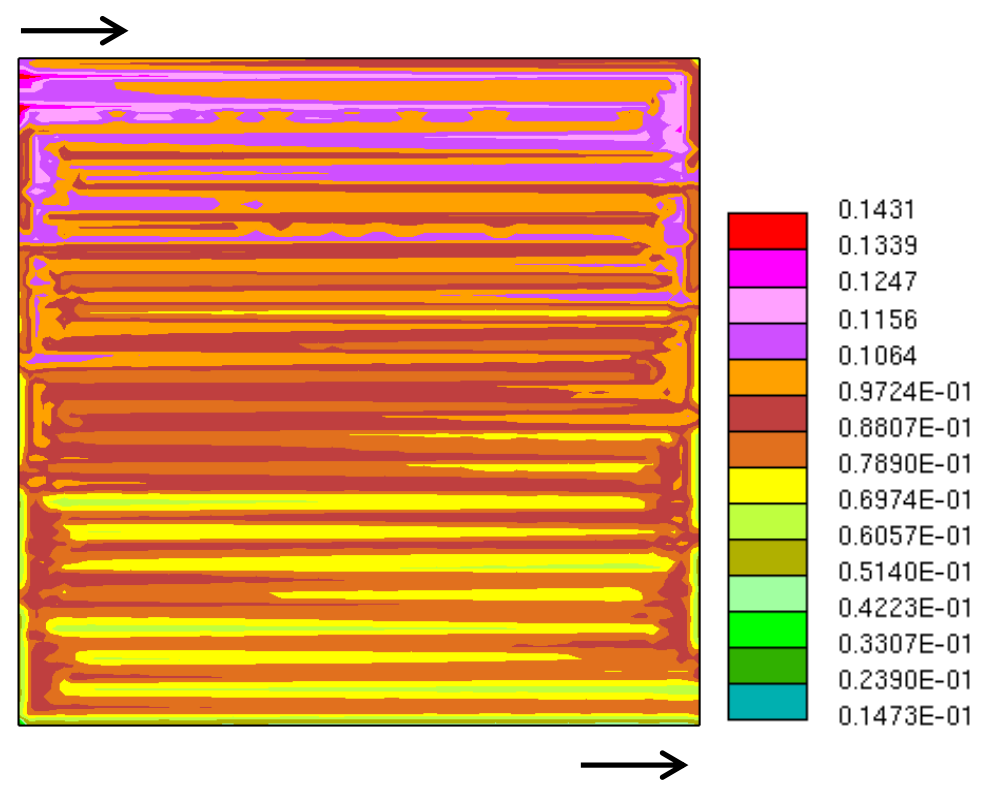

c) Anode $100 \% \mathrm{RH}$, Cathode $50 \% \mathrm{RH}, 5 \mathrm{psig}$

Figure 11. Net water flux across the membrane $\left(\mathrm{mg} / \mathrm{cm}^{2}-\mathrm{s}\right)$ of three different inlet humidity conditions at potential of $0.3 \mathrm{~V}$. a) Anode $25 \% \mathrm{RH}$, Cathode $25 \% \mathrm{RH}$, b) Anode $75 \% \mathrm{RH}$, Cathode 25\%RH, and c) Anode 100\%RH, Cathode 50\%RH, 5 psig. 


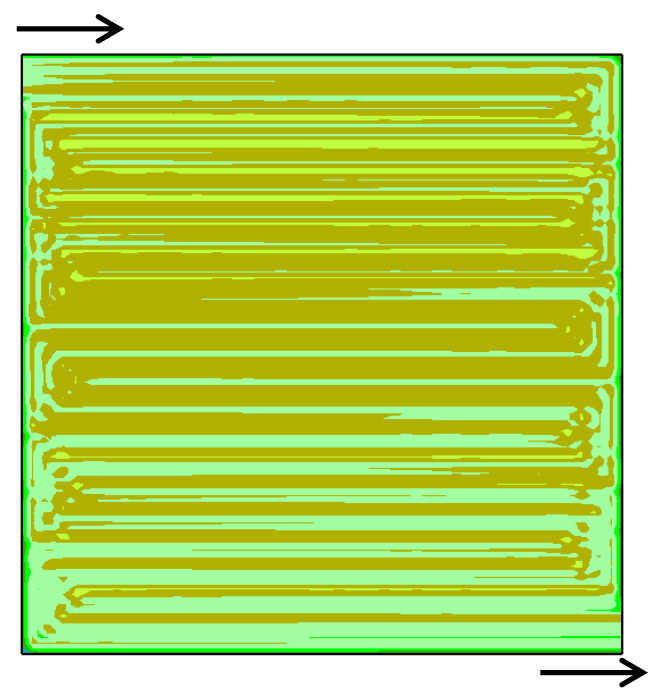

a) Anode $25 \% \mathrm{RH}$, Cathode $25 \% \mathrm{RH}$

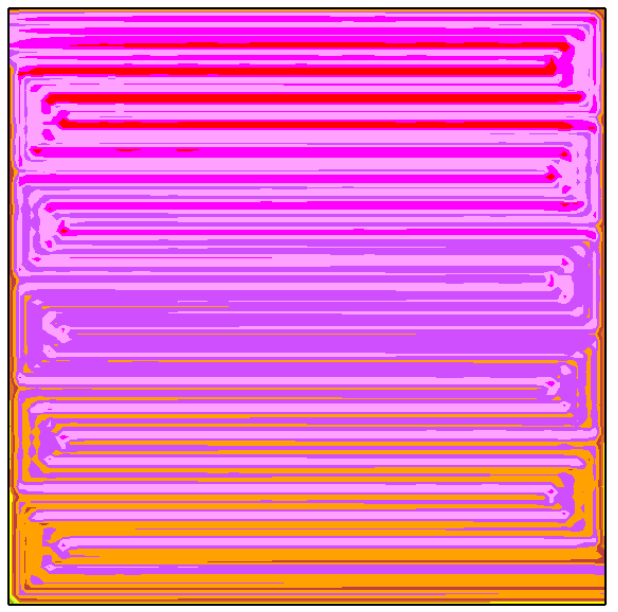

c) Anode $100 \% \mathrm{RH}$, Cathode $50 \% \mathrm{RH}, 5 \mathrm{psig}$

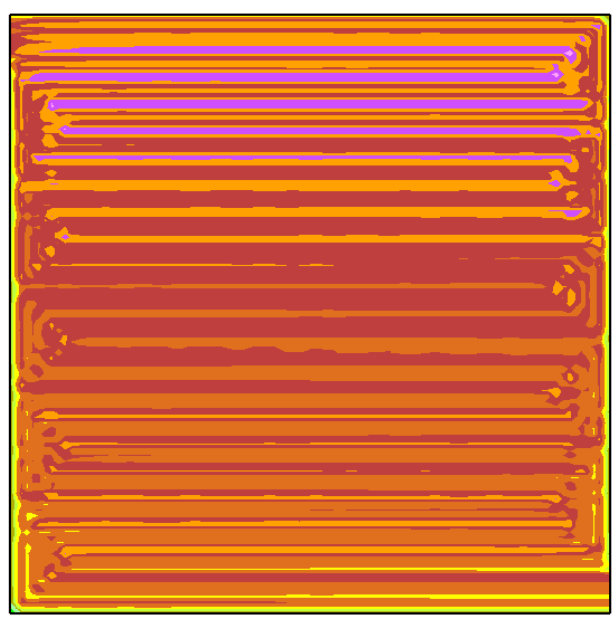

b) Anode $75 \% \mathrm{RH}$, Cathode $25 \% \mathrm{RH}$

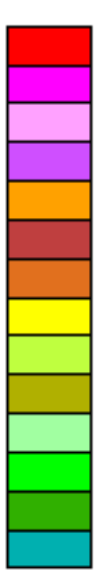

368.0

367.2

366.4

365.6

364.9

364.1

363.3

362.5

361.7

360.9

360.1

359.4

358.6

357.8

357.0

Figure 12.Temperature (K) distribution on cathode MEA surface of three different inlet humidity conditions at potential of $0.3 \mathrm{~V}$. a) Anode $25 \% \mathrm{RH}$, Cathode $25 \% \mathrm{RH}, \mathrm{b}$ ) Anode 75\%RH, Cathode 25\%RH, and c) Anode 100\%RH, Cathode 50\%RH, 5 psig. 